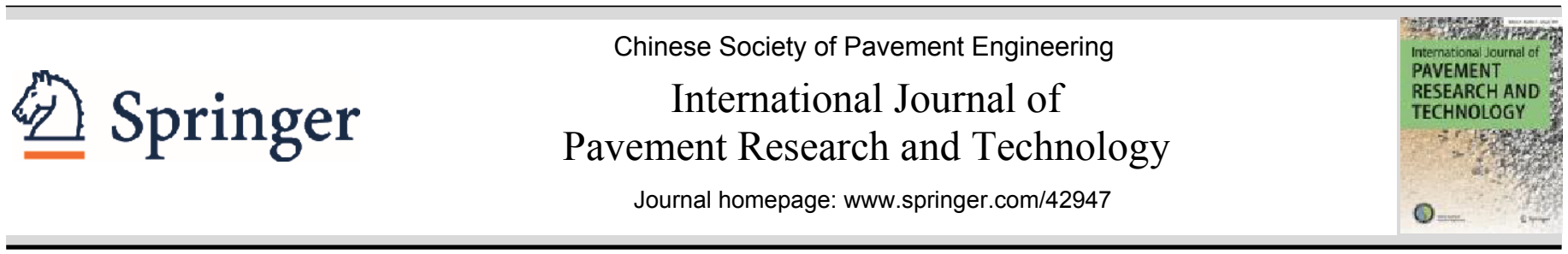

\title{
Erratum to: A review on the mechanisms involved in reclaimed asphalt pavement
}

\author{
Lekhaz Devulapalli, Saravanan Kothandaraman*, Goutham Sarang \\ School of Mechanical and Building Sciences, Vellore Institute of Technology, Chennai-600127, India
}

Received 2 May 2018; received in revised form 5 October 2018; accepted 20 December 2018; Published online 30 April 2019

\section{Erratum}

After publication of this work [1], we noted that we misspelled the Corresponding author's name Saravanan K. Kothandaraman and has now been updated. We are publishing this erratum to update the Corresponding author's name as Saravanan Kothandaraman.

\section{Notes}

The original article has been corrected

The online version of the original article can be found under doi: 10.1007/s42947-019-0024-1.

The online version of the original article can be found at https://doi.org/10.1007/s42947-019-0024-1

\section{Reference}

[1] Devulapalli, L., Kothandaraman, S. \& Sarang, G. Int. J. Pavement Res. Technol. (2019) 12: 185.

\footnotetext{
* Corresponding author

Peer review under responsibility of Chinese Society of Pavement Engineering.

E-mail addresses: lekhaz.devulapalli@gmail.com (Lekhaz Devulapalli); saravanan@vit.ac.in (Dr Saravanan. K).. 